\title{
Ground mobile observation system for measuring multisurface microwave emissivity
}

\author{
Wenying He ${ }^{1 *, 2}$ Hongbin Chen ${ }^{1,2}$ Yuejian Xuan ${ }^{1} \quad$ Jun Li $^{1} \quad$ Minzheng Duan ${ }^{1,2}$ \\ 1.Key Laboratory of Middle Atmosphere and Global Environment Observation, Institute of \\ Atmospheric Physics, Chinese Academy of Sciences, Beijing 100029, China \\ 2.University of Chinese Academy of Sciences, Beijing 100049, China
}

\section{Abstract}

Large microwave surface emissivities with a highly heterogeneous distribution make it challenging to use satellite microwave data to retrieve precipitation and to be assimilated into numerical models over land. To better understand the microwave emissivity over land surfaces, we designed and established a ground observation system for the in situ observation of microwave emissivities over several typical surfaces. The major components of the system include a dual-frequency polarized ground microwave radiometer, a mobile observation platform, and auxiliary sensors to measure the surface temperature and soil temperature and moisture; moreover, observation fields are designed comprising five different land surfaces.

Based on the observed data from the mobile system, we preliminarily investigated the variations in the surface microwave emissivity over different land surfaces. The results show that the horizontally polarized emissivity is more sensitive to land surfaces than is the vertically polarized emissivity: the former decreases to 0.75 over cement and increases to 0.90 over sand and bare soil and up to 0.97 over grass. The corresponding emissivity polarization difference is obvious over water $(>0.3)$ and cement (approximately 0.25 ) but reduces to 0.1 over sand and 0.05 over bare soil and almost 0.01 or close to zero over grass; this trend is similar to that of the $\mathrm{Tb}$ 
polarization difference. At different elevation angles, the horizontally/vertically polarized emissivities over land surfaces obviously increase/slightly decrease with increasing elevation angle but exhibit the opposite trend over water.

Key words: Ground mobile observation system, microwave radiometer, microwave surface emissivity, surface temperature, land surface

\section{Introduction}

The land surface microwave emissivity varies but is generally high $(\sim 0.90)$ and thus generates strong surface radiance; however, this strong surface radiance obscures the atmospheric radiance, making it more difficult to assimilate and precisely retrieve atmospheric parameters using satellite microwave data over land (McNally et al., 2000; Farbou et al., 2005; Schwartz et al., 2012). Moreover, due to complex variations affected by many surface factors, such as soil type, wetness, vegetation type and surface roughness, the land surface emissivity is poorly understood. Hence, the land surface microwave emissivity constitutes a major parameter limiting the application of spaceborne microwave data over land.

Microwave emissivity models have been developed only for a limited range of frequencies and surface conditions. For example, the emissivity over bare soil was modeled at lower frequencies, and the soil dielectric constants were obtained from ground-based measurements (Wang and Schmugge, 1980). Furthermore, the emissivity over the vegetation canopy was simulated using a radiative transfer model with a large number of canopy optical parameters (Mo and Schmugge, 1987; Isaacs et al., 1989; Fung, 1994). Weng (2001) developed a microwave land emissivity model to 
quantify the emissivity over various surface conditions, including snow, deserts, and vegetation. Xie et al. (2017) developed a parameterized soil surface emissivity model for bare soil surfaces and compared with Weng's model, results reflected the reduced overall errors, especially for horizontal polarization. Ultimately, the microwave emissivity of land surfaces is determined mainly by the soil dielectric constant, which is influenced by the physical temperature, soil texture and moisture content, and vegetation structure and type. As a result of these complicated parameters with numerous uncertainties, establishing a common physical emissivity model and accurately obtaining emissivity estimates by using only an emissivity model remain challenging.

Satellite observations offering extensive coverage have been used to estimate the regional and global distributions of land surface emissivity since the 1990s (Prigent et al., 2000; Moncet et al., 2011). To avoid the impacts of the complex variability of clouds and precipitation in the atmosphere, only the brightness temperatures observed by spaceborne microwave instruments under clear sky conditions are generally selected to calculate the land surface microwave emissivity. Jones and Vonder Haar (1997) used SSM/I (Special Sensor Microwave Imager) microwave observations and GOES/VISSR (Geostationary Operational Environmental Satellite/Visible Infrared Spin-Scan Radiometer) infrared data that were closely matched in both space and time to retrieve the microwave land emissivity over the Central United States and utilized the infrared data with a constant infrared emissivity of 0.98 to calculate the land skin temperature (LST) under clear sky conditions. Further, Ruston and Vonder Haar (2004) 
71 directly employed spatially varying infrared surface emissivities in the retrieval of

72 LST to calculate the microwave emissivity and discovered that the

atmospheric-corrected microwave surface emissivity is valuable for determining land surface characteristics but is sensitive to rain events. Prigent et al. $(1997,1999)$ calculated the land surface microwave emissivity over Africa, some parts of Europe and West Asia by combining SSM/I data with LST observations provided by ISCCP (International Satellite Cloud Climatology Project). With subsequently improved ISCCP LST and cloud product data, Prigent et al. (2006) presented a global land surface microwave emissivity database retrieved from 10 years of SSM/I data and plotted the monthly average land surface microwave emissivity onto a geographic map. In their work, the microwave emissivity retrieval was based primarily on radiative transfer calculations, in which infrared data were used to determine the LST under clear sky conditions, and atmospheric sounding data were used to take the effects of atmospheric attenuation into account. Nevertheless, due to the complexity and variability of clouds and atmospheric precipitation, land surface microwave emissivity estimates derived from satellite observations are available only under clear sky conditions. Moreover, the cloud screening and LST retrieval methods still contain numerous uncertainties, which represent the main sources of errors in emissivity calculations.

At present, the accuracy of surface emissivity estimates calculated from either emissivity models or satellite observations is limited by the complexity of the land surface and the variability of vegetation types and soil moisture. Hence, surface 
93 emissivity calculations need to be verified and improved with more in situ observation

94 data.

To better understand the variation characteristics of surface emissivity with surface conditions, Ulaby et al. (1985) combined field experiments and theoretical research and revealed that the land surface microwave specific emissivity is strongly correlated with the distributions of soil moisture and vegetation. In addition, a few observation experiments using ground-based microwave radiometers have been carried out since the 1990s to study the variation characteristics of emissivity over different surfaces (Njoku and O'Neill,1982; Matzler, 1990, 1994; Calvet, 1997; Wigneron, 1994; Morland et al., 1995). More recently, in situ passive microwave radiometer measurements over snow cover and sub-Arctic frozen soil have been used to validate empirical emission models (Lemmetyinen et al., 2015; Montpetit et al., 2018). Additionally, an aircraft-flown microwave radiometer was used to directly observe the surface emissivity over forests, crops, snow and ice to analyze the sensitivity of those emissivities to the view angle, frequency, measurement time and surface characteristics (Hewison, 2001; Wigneron et al., 1997; Hewison and English, 1999).

The observation mode of a microwave radiometer in a field experiment is an important consideration. Usually, ground-based radiometers are fixed when scanning the observed field; for example, they can be mounted on a truck or a tower (Matzler, 1990; Lemmetyinen et al., 2015), allowing the instrument to better determine the temporal evolution of surface emissivity over single type of land-cover area. In 

easy to obtain long-term emissivity observations due to the high cost and effort.

To obtain the long-term temporal evolution of surface emissivity over different types of surfaces simultaneously, we proposed and developed a ground mobile observation system to enhance in situ microwave emissivity observations. Long-term continuous emissivity field experiments can help to more accurately understand the characteristics of passive microwave polarized emissivities over typical land surfaces, form a benchmark for verifying the retrieved emissivities from satellite or emission models, and establish an emissivity parameterization scheme for a given surface in radiance assimilation. The outline of this paper is as follows: the design of the ground mobile observation system for measuring surface emissivity is introduced in section 2; the data and method used for the emissivity calculations are described in section 3 ; then, the surface emissivity estimates obtained directly from the observation system are discussed preliminarily in section 4; and a final short summary is given in section 5. over 5 test plots. Fig. 1 is an on-site photo of the observation system operating at the Xianghe observation site $\left(116.98^{\circ}\right.$ E, $\left.39.76^{\circ} \mathrm{N}\right)$, Hebei Province, China. As shown in 
137 Fig. 1, the mobile observation system consists of five main parts: a dual-polarized

138 ground-based microwave radiometer to observe the surface and sky radiances, a mobile platform to move back and forth along a track, and three auxiliary sensors to measure the surface temperature, soil temperature and moisture. The observation field includes five test plots, namely, water, cement, sand, bare soil and grass. From the observation system, we can directly obtain surface microwave emissivity estimates more accurately than is possible from satellite data or emissivity models, which is important to properly understand the variation characteristics of land microwave emissivities and to improve the emissivity parameterization schemes used in models.

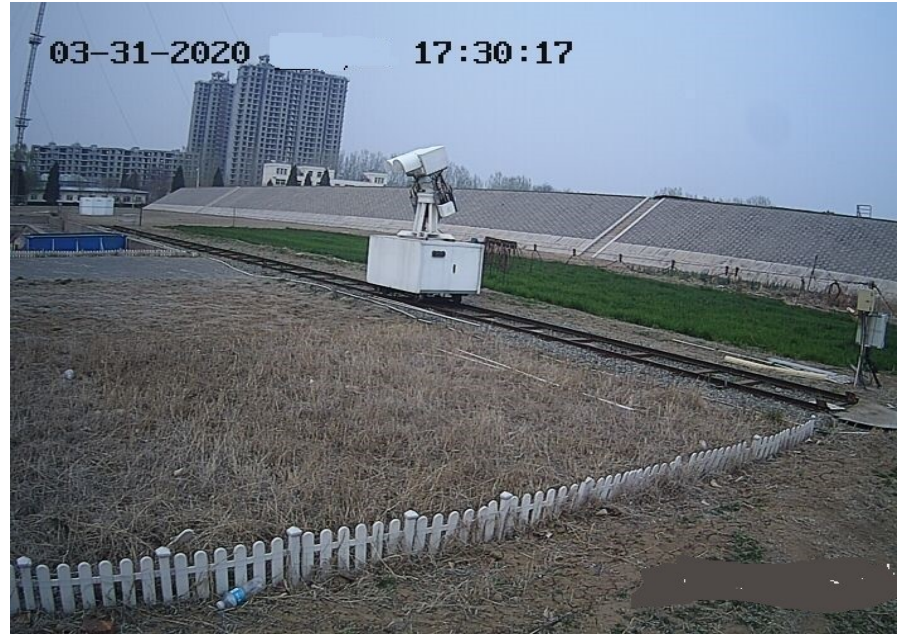

Fig 1 On-site photo of the surface microwave emissivity observation system operating over various surfaces at the Xianghe site, China

\subsection{Ground-based microwave radiometer}

The core device of the observation system is a dual-frequency (18.7 and 36.5 $\mathrm{GHz}$ ), dual-polarized (horizontal and vertical) microwave radiometer (RPG-4CH-DP) produced by Radiometer Physics GmbH, Germany. The RPG-4CH-DP radiometer is a 
high-performance instrument with a direct detection receiver and a completely automatic calibration system. The radiometer is mounted on an accurate elevation/azimuth positioner so that the whole system can perform scans in any direction from the sky to the ground, thereby realizing complex scanning schemes, such as all-sky monitoring and all-round monitoring of the ground. The RPG-4CH-DP can distinguish cloud/raindrop particles during precipitation and monitor soil moisture and vegetation parameters by using signals with different polarizations. Both frequencies of $18.7 \mathrm{GHz}$ and $36.5 \mathrm{GHz}$ have been widely combined to detect snow depth and snow water content and are frequently used in most spaceborne microwave imagers, such as the SSM/I, AMSR-E (Advanced Microwave Scanning Radiometer for EOS) and GMI (Greenhouse gases Monitoring Instrument) sensors. The directly observed surface emissivities at these two frequencies can provide highly accurate references for the verification and assimilation of spaceborne microwave observations.

The RPG-4CH-DP radiometer has a comparable half-power beam width of approximately $6^{\circ}$ and a calibration accuracy of $\pm 1 \mathrm{~K}$. Currently, the height of the instrument above the ground is $2.5 \mathrm{~m}$, which results in a half-power footprint width of $0.22 \mathrm{~m}$ on average. More details regarding the instrument specifications for the RPG-4CH-DP are shown in Table 1.

Table 1 Instrument Specifications

\begin{tabular}{|l|l|}
\hline \multicolumn{1}{|c|}{ Parameter } & \multicolumn{1}{c|}{ Specification } \\
\hline Radiometric resolution & $0.2 \mathrm{~K} \mathrm{RMS}(1.0 \mathrm{~s}$ integration time $)$ \\
\hline Optical resolution & HPBW: $6.0^{\circ}($ Sidelobe level $<-30 \mathrm{dBc})$ \\
\hline
\end{tabular}




\begin{tabular}{|l|l|}
\hline Absolute system stability & $1.0 \mathrm{~K}$ \\
\hline Receiver and antenna thermal stabilization & Accuracy $<0.05 \mathrm{~K}$ \\
\hline Pointing speed & Elevation: $3^{\circ} / \mathrm{sec}$, azimuth: $5^{\circ} / \mathrm{sec}$ \\
\hline Radiometric range & $0-350 \mathrm{~K}$ \\
\hline Operating temperature range & $-40^{\circ} \mathrm{C}$ to $+45^{\circ} \mathrm{C}$ \\
\hline Power consumption & $<350$ watts on average, 500 -watt peak \\
\hline Weight & $105 \mathrm{~kg}$ for receiver modules, $300 \mathrm{~kg}$ for positioner \\
\hline
\end{tabular}

Currently, the RPG-4CH-DP provides only the basic brightness temperature (Tb) data in 4 channels without other related products. By incorporating the auxiliary observations from the observation system, we broadened the application of the instrument, denoted RPG-XCH-DP, thereby providing not only the basic microwave radiance but also the complex surface emissivity.

\subsection{Mobile system (platform)}

The multitarget mobile system comprises a track, a mobile platform, a driving system and a control unit. As the sketch of the mobile system in Fig. 2 shows, the 25 $\mathrm{m}$ track is parallel to the test plots with an observation interval of $0.3 \mathrm{~m}$. The mobile platform placed on the track is a metal box $4 \mathrm{~m}$ in length, $0.8 \mathrm{~m}$ in height, and $1.0 \mathrm{~m}$ in depth. The driving system includes a stepper motor, transmission mechanism, and communication cable connected to the mobile platform and power supply. The control unit consists of a single-chip microcomputer, timer and stepper motor driver, which can set the moving time and control the operation of the driving device. The control device is installed on the mobile platform and connects both driving devices.

In this experiment, to obtain the microwave emissivity over different surfaces in near-simultaneous time, the RPG-4CH-DP is mounted on the mobile platform and moves back and forth along the track. The communication system for receiving the data and the power supply are placed in the metal box. According to the commands from the single-chip microcomputer and the driving force from the stepper motor, the mobile platform moves along the track similar to a small train, and the onboard 
radiometer scans the 5 test plots at fixed times every day.

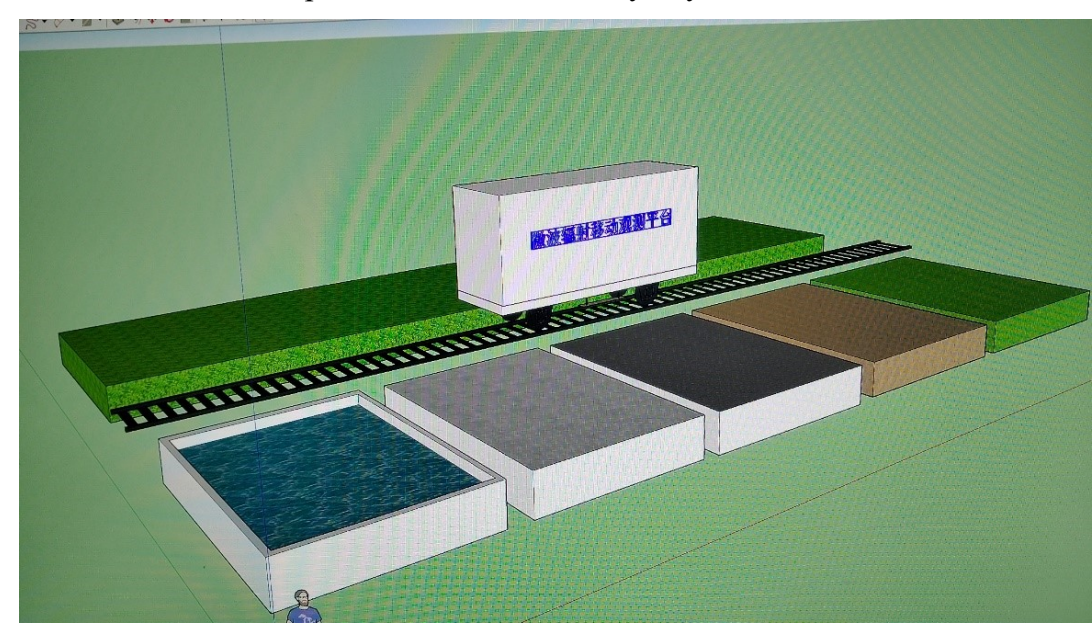

Fig. 2 Sketch of the mobile platform

\subsection{Observation field and auxiliary data}

Fig. 3 shows a sketch of the observation field, including the 5 test plots distributed along the $25 \mathrm{~m}$ track. Currently, 5 surface types are considered in the observation field, namely, water, cement, sand, soil and grass. For the water body, a plastic pool $6 \mathrm{~m}$ long and $2.4 \mathrm{~m}$ wide is used to hold the water. The adjacent cement surface consists of a $2 \mathrm{~m}$ wide footpath. The remaining three plots of sand, bare soil and grass are the same size (approximately $6 \mathrm{~m}$ long by $4 \mathrm{~m}$ wide) and are separated by a distance of approximately $2 \mathrm{~m}$.

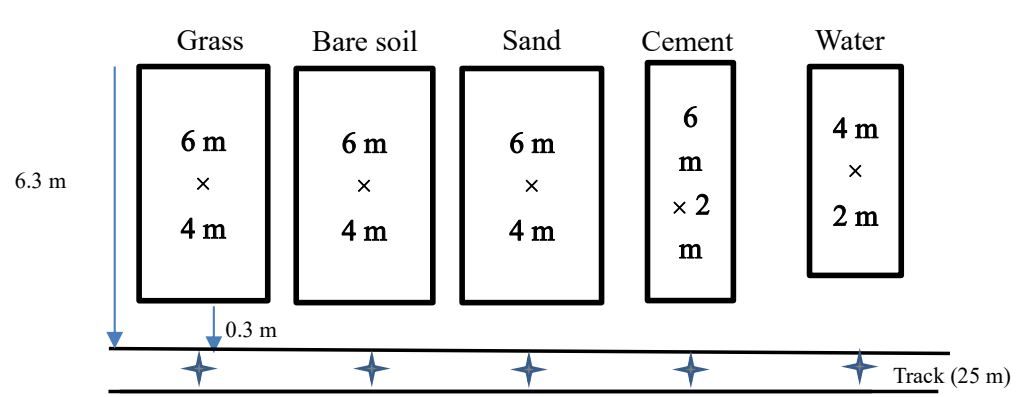

Fig. 3 Sketch of the observation field (including 5 test plots: water, cement, sand, bare soil and grass), where denotes the positiontof a touching switch

To scan each plot at the same place at a fixed time, five touching switches 
corresponding to the center of each plot are fixed on the track to stop the moving platform so that the radiometer can scan the same place for a couple of minutes. By using this mobile platform, the ground-based radiometer can scan multiple surfaces almost simultaneously (i.e., within $1 \mathrm{hr}$ ), thereby providing valuable measurements for understanding the variation in surface emissivity over different land surfaces with different characteristics.

The auxiliary data include mainly the surface temperature, soil temperature and soil moisture. Five thermometers with a PT100 temperature sensor made by Honeywell company are placed separately on each test plot to measure their surface temperature. In addition, an SI-111 precision infrared radiometer developed by Apogee Instruments Inc. is fixed on a stand of the RPG-4CH-DP radiometer to obtain the surface temperature of each plot while the microwave radiometer is moving. Furthermore, a set of soil temperature and humidity sensors is fixed at three soil depths, $5 \mathrm{~cm}, 10 \mathrm{~cm}$ and $20 \mathrm{~cm}$, to detect the subsurface soil temperature and humidity. To monitor the real-time working situation of the whole observation system, a digital video camera is installed near the field to record the states of the mobile platform and radiometer as well as changes in the weather, such as the presence of cloud cover, rain or snow.

\subsection{Scanning mode}

To directly obtain the surface emissivity, a combined mode of ground observations at multiple elevation angles and zenith observations is designed, in which the former monitors mainly the surface radiance while the latter monitors the sky radiance in the same $1 \mathrm{hr}$ period.

The ground observation mode is illustrated in Fig. 4. The mobile platform is triggered every hour, and the microwave radiometer operates using the ground scanning mode at this time. The scan is performed from the horizon $\left(0^{\circ}\right)$ to the ground, and the elevation angle is defined as the angle between the scanning direction and the horizontal. A negative value indicates an angle below the horizon, which is equivalent to $90^{\circ}-\theta$, where $\theta$ is the incident angle, an important parameter for describing spaceborne radiometer scanning. The radiometer is $2.5 \mathrm{~m}$ above the ground, so it can 


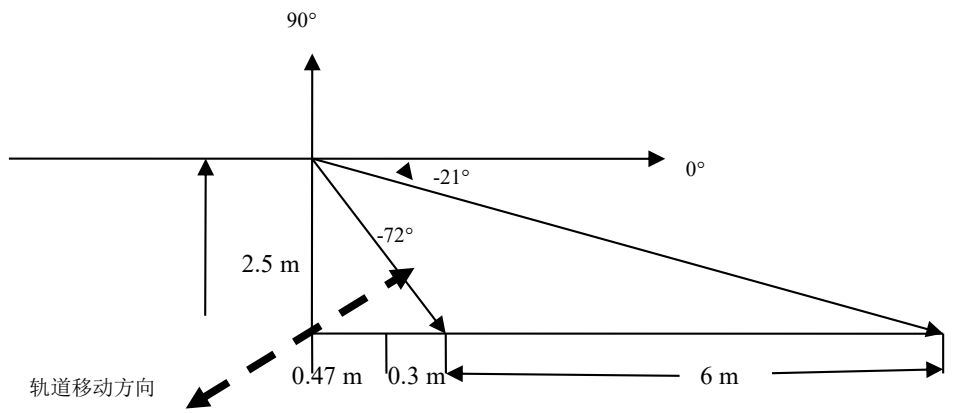

scan each test plot with a length of $6 \mathrm{~m}$ when the elevation angle is between $-21^{\circ}$ and $-72^{\circ}$, as shown in Fig. 4. The valid elevation angle range for water is different due to the different length of the pool. To determine the surface emissivity variation with the elevation angle, the radiometer is set to scan each test plot with an angle interval of $3^{\circ}$ from $-21^{\circ}$ to $-45^{\circ}$, an angle interval of $5^{\circ}$ from $-45^{\circ}$ to $-70^{\circ}$, and then back to $-21^{\circ}$ to scan the test plot repeatedly during the ground observation mode. To acquire ground observations over all 5 test plots within $1 \mathrm{hr}$, each plot is given 9 minutes; in other words, the mobile platform will move to the cement plot at $9 \mathrm{~min}$, the sand plot at 18 min, the bare soil plot at $27 \mathrm{~min}$, and finally the grass plot at $36 \mathrm{~min}$. After finishing the ground observations in all 5 test plots, the mobile platform will begin to move back at $45 \mathrm{~min}$ and reach the beginning location after approximately 6 min. During the return trip, the scan mode changes to the zenith observation mode so that the radiometer scans from the ground to the sky. When the elevation angle is raised to $90^{\circ}$, the radiometer will continually acquire zenith observations for approximately $5 \mathrm{~min}$ to obtain the sky radiance. After obtaining these zenith observations, the elevation angle changes from the zenith observation mode to the ground observation mode at $-21^{\circ}$ so that the radiometer is already in the ground observation mode when the next measurement cycle arrives. In this way, the radiometer on the mobile platform can obtain not only the ground radiance over 5 test plots but also the sky radiance within a 
differences in the surface and sky radiance, and thus, the mobile system can obtain the microwave emissivity over different surfaces nearly simultaneously.

\section{Data and method}

Three types of observation data are obtained from the field experiment: the microwave brightness temperature $(\mathrm{Tb})$ at different scanning angles from the ground microwave radiometer; the surface temperature (Ts) of the five test plots measured from the ground thermometers and infrared sensor; and the soil temperature and moisture at three depths in the sand and bare soil plots.

When ground microwave radiometer scans the surface, the measured $\mathrm{Tb}$ comes mainly from two contributions: that of upward radiation from the surface and that of the reflected downward atmospheric radiance. Thus, the measured $\mathrm{Tb}$ can be approximately expressed by Eq. (1):

$$
\mathrm{T}_{\mathrm{b}}=\varepsilon \mathrm{T}_{\mathrm{s}}+(1-\varepsilon) \mathrm{T}_{\text {sky }}
$$

where $\varepsilon$ is the surface emissivity, $T_{\mathrm{s}}$ is the surface temperature, and $\mathrm{T}_{\text {sky }}$ is the radiance from the sky. From Eq. (1), the surface emissivity can be directly calculated using Eq. (2) by combining the $\mathrm{Tb}$ contributions from the surface and sky with the surface temperature synchronously measured from the infrared sensor in the observation system.

$$
\varepsilon=\left(\mathrm{T}_{\mathrm{b}}-\mathrm{T}_{\text {sky }}\right) /\left(\mathrm{T}_{\mathrm{s}}-\mathrm{T}_{\text {sky }}\right)
$$

Through applying the ground mobile observation system for surface microwave emissivity and combining the video camera records with the soil temperature and moisture measurements, we can not only directly obtain highly accurate surface microwave emissivity observations over different test plots but also investigate the variation characteristics of the surface emissivity under different weather conditions.

\section{Preliminary results}

Considering both the viewing field of the microwave radiometer and the size of the 
test plots, the elevation angle range between $-24^{\circ}$ and $-65^{\circ}$ is chosen for observing the

301 land test plots (cement, sand, soil and grass), while elevation angles between $-33^{\circ}$ and $-65^{\circ}$ are valid for observing the water surface. Here, we focus on the variations in the radiance and surface emissivity over the 5 test plots during the observations recorded in October 2018 under clear sky conditions.

\subsection{Radiance}

Since a scanning angle of $36^{\circ}$ is equivalent to an incident angle of $54^{\circ}$ used for many spaceborne microwave imagers, such as AMSR-E $\left(55^{\circ}\right)$ or SSM/I $\left(53^{\circ}\right)$, we first compare the variation in the observed $\mathrm{Tb}$ over different surfaces at an elevation angle of $36^{\circ}$. The changes in the observed $\mathrm{Tb}$ at $36.5 \mathrm{GHz}$ in horizontal ( $\left.\mathrm{Tb} 36 \mathrm{~h}\right)$ and vertical (Tb36v) polarization over the four land surfaces within $24 \mathrm{hr}$ (Beijing Time, BJT) are quite similar, with smaller values at night and larger values at noon. Less variation in the radiance is noted at $\mathrm{Tb} 36 \mathrm{v}$ (not shown), but more significant variations are detected at Tb36h over the four surfaces as shown in Fig. 5a: the observed Tb36h from grass is approximately $270-285 \mathrm{~K}$ but varies within $240-270 \mathrm{~K}$ over sand and bare soil and reaches only $200-230 \mathrm{~K}$ for cement. The observed $\mathrm{Tb}$ at $18.75 \mathrm{GHz}$ within $24 \mathrm{~h}$ shows similar variations with only slight changes among the different land surfaces. Likewise, the corresponding polarization differences $(\mathrm{V}-\mathrm{H})$ of $\mathrm{Tb}$ within $24 \mathrm{hr}$ are very similar to one another, so both DTb18vh and DTb36vh at 02:00

319 (BJT) are shown in Fig. 5b, revealing a slight difference (close to zero) for grass but considerably larger differences for water and cement (almost up to $70 \mathrm{~K}$ for water) and smaller differences over sand and soil (below $30 \mathrm{~K}$ ). In addition, the values of 
DTb18vh are larger than those of DTb36vh. The Tb polarization difference is more other three land surfaces and thus scatters more surface radiance and reduces the polarization difference. Therefore, the observed $\mathrm{Tb}$ polarization differences over the identifying land surfaces and water bodies.
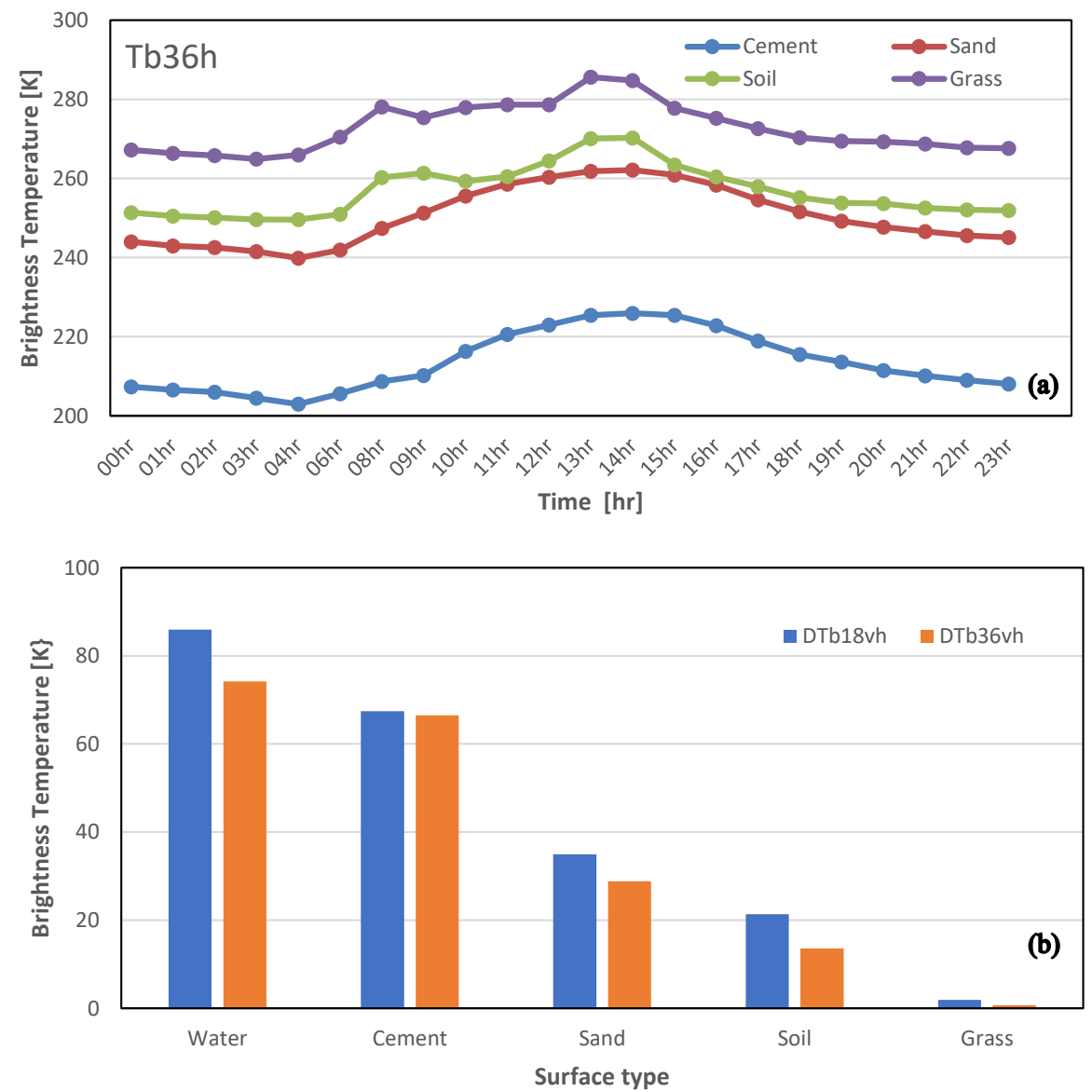
Fig. 5 Variations in the observed $\mathrm{Tb}$ (a) and $\mathrm{Tb}$ polarization differences (b) over

333 different surfaces in October 2018.

334 To study the variations in $\mathrm{Tb}$ at more than a single angle, Fig. 6a shows the changes in the observed $\mathrm{Tb}$ with the elevation angle ranging from $24^{\circ}$ to $65^{\circ}$ over the four land surfaces. The horizontally polarized $\mathrm{Tb}$ is clearly more sensitive to land surfaces than the vertically polarized $\mathrm{Tb}$ with increasing elevation angle; in particular, $\mathrm{Tb} 36 \mathrm{~h}$ rises rapidly from $180 \mathrm{~K}$ to $240 \mathrm{~K}$ over cement but slowly increases from $240 \mathrm{~K}$ to $260 \mathrm{~K}$ over sand and bare soil and remains almost constant over grass. In contrast, the variations in the vertically polarized $\mathrm{Tb}$ with increasing elevation angle are similar among the land surfaces and are smaller than those in the horizontally polarized $\mathrm{Tb}$, showing a decreasing trend from $280 \mathrm{~K}$ to $260 \mathrm{~K}$ over different surfaces. In addition, the variations in the observed Tb over water are presented in Fig. 6b. Different from the above observations over land surfaces, the vertically polarized $\mathrm{Tb}$ over water obviously reduces from $200 \mathrm{~K}$ to $140 \mathrm{~K}$ with increasing elevation angle, while the horizontally polarized $\mathrm{Tb}$ slowly rises from $100 \mathrm{~K}$ to $120 \mathrm{~K}$, almost opposite to the $\mathrm{Tb}$ polarization variations over land surfaces. The corresponding changes in the polarization difference of $\mathrm{Tb}$ at $18.75 \mathrm{GHz}(\mathrm{DTb} 18 \mathrm{vh})$ over all 5 classes of surfaces are further plotted in Fig. 6c. In general, the Tb polarization difference decreases with increasing elevation angle, and the variated ranges with the elevation angle over the 5 classes surfaces in Fig. 6c are similar to those in Fig.5b; thus, the decreasing trend is most obvious over water and cement and lest evident over grass with increasing elevation angle. Furthermore, the variations of the Tb polarization difference at 36.5 
$\mathrm{GHz}$ with the elevation angle are similar to those at $18.75 \mathrm{GHz}$ over all 5 test plots.
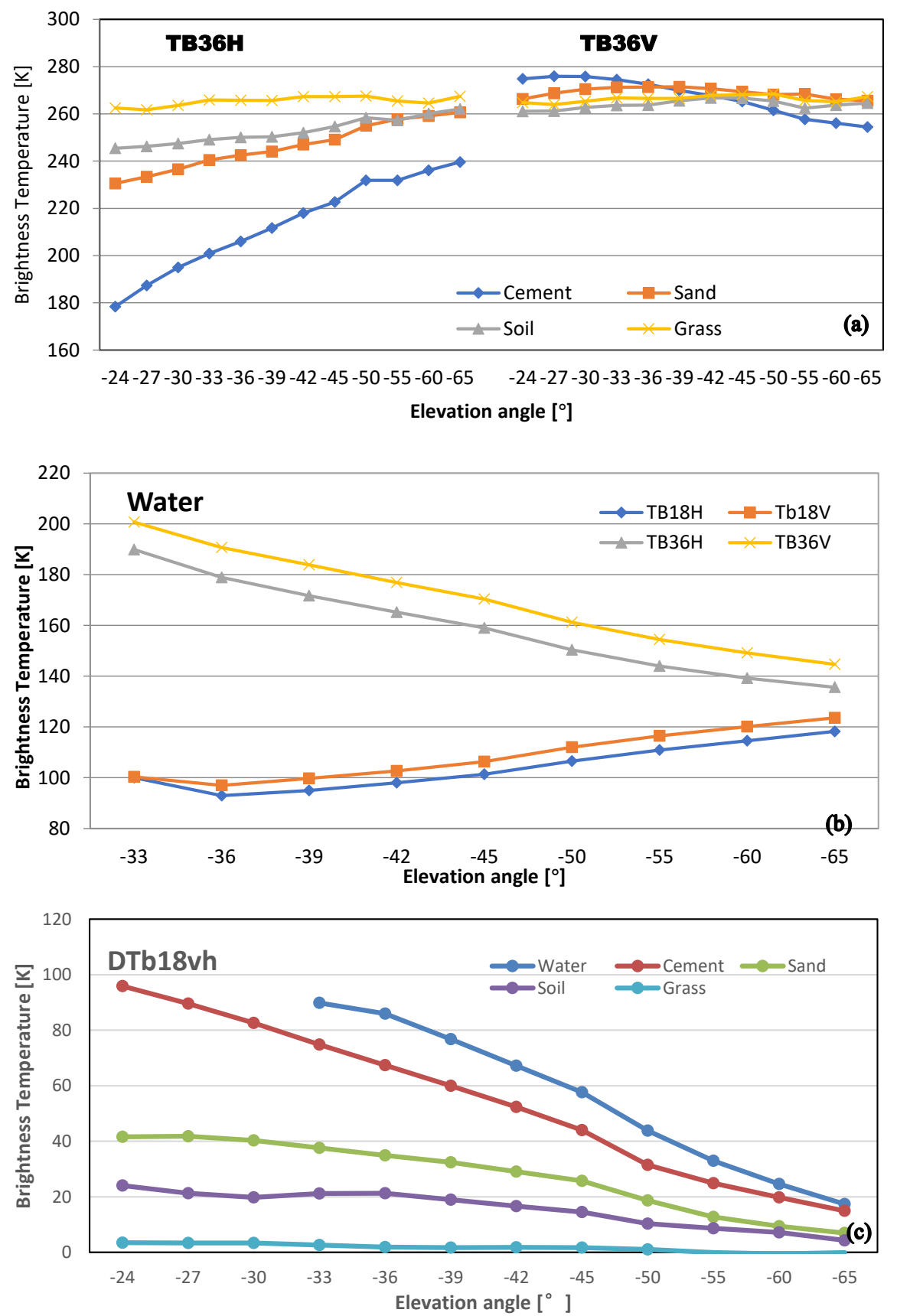

Fig. 6 Variations in the observed radiance over different land surfaces with the 


\subsection{Surface microwave emissivity}

Combining the surface and sky radiance contributions to $\mathrm{Tb}$ with the surface temperature derived from the infrared sensor, the surface emissivity $(\varepsilon)$ is derived from Eq. (2). Since the diurnal variation of $\varepsilon$ is more constant and less significant than that of the $\mathrm{Tb}$ radiance, the surface emissivity observed at 02:00 (BJT) is chosen for the following investigation. First, the polarized $\varepsilon$ at both 18.75 and $36.5 \mathrm{GHz}$ and their polarization differences at an elevation angle of $36^{\circ}$ are compared in Fig. 7a. The vertically polarized $\varepsilon\left(\varepsilon_{\mathrm{v}}\right)$ is clearly much larger than the horizontally polarized $\varepsilon\left(\varepsilon_{\mathrm{h}}\right)$, and the $\varepsilon$ values at the same frequencies are close, but the $\varepsilon$ values over water is smaller than those over the four land surfaces. The $\varepsilon_{\mathrm{h}}$ values obviously differ among the 4 land surfaces, although their corresponding $\varepsilon_{\mathrm{v}}$ values are relatively similar, exceeding 0.95 , which indicates that $\varepsilon_{\mathrm{h}}$ is more sensitive to land surfaces than $\varepsilon_{\mathrm{v}}$. The $\varepsilon_{\mathrm{h}}$ is lower than 0.75 over cement but increases to 0.90 over sand and bare soil and up to 0.97 over grass. Thus, the polarization difference $\left(\varepsilon_{v}-\varepsilon_{\mathrm{h}}\right)$ shown in Fig. $7 \mathrm{~b}$ is obvious over water $(>0.3)$ and cement (approximately 0.25$)$ but reduces to 0.1 over sand and 0.05 over bare soil and almost 0.01 or close to zero over grass; this trend is similar to that of the $\mathrm{Tb}$ polarization difference shown in Fig. $5 \mathrm{~b}$. 

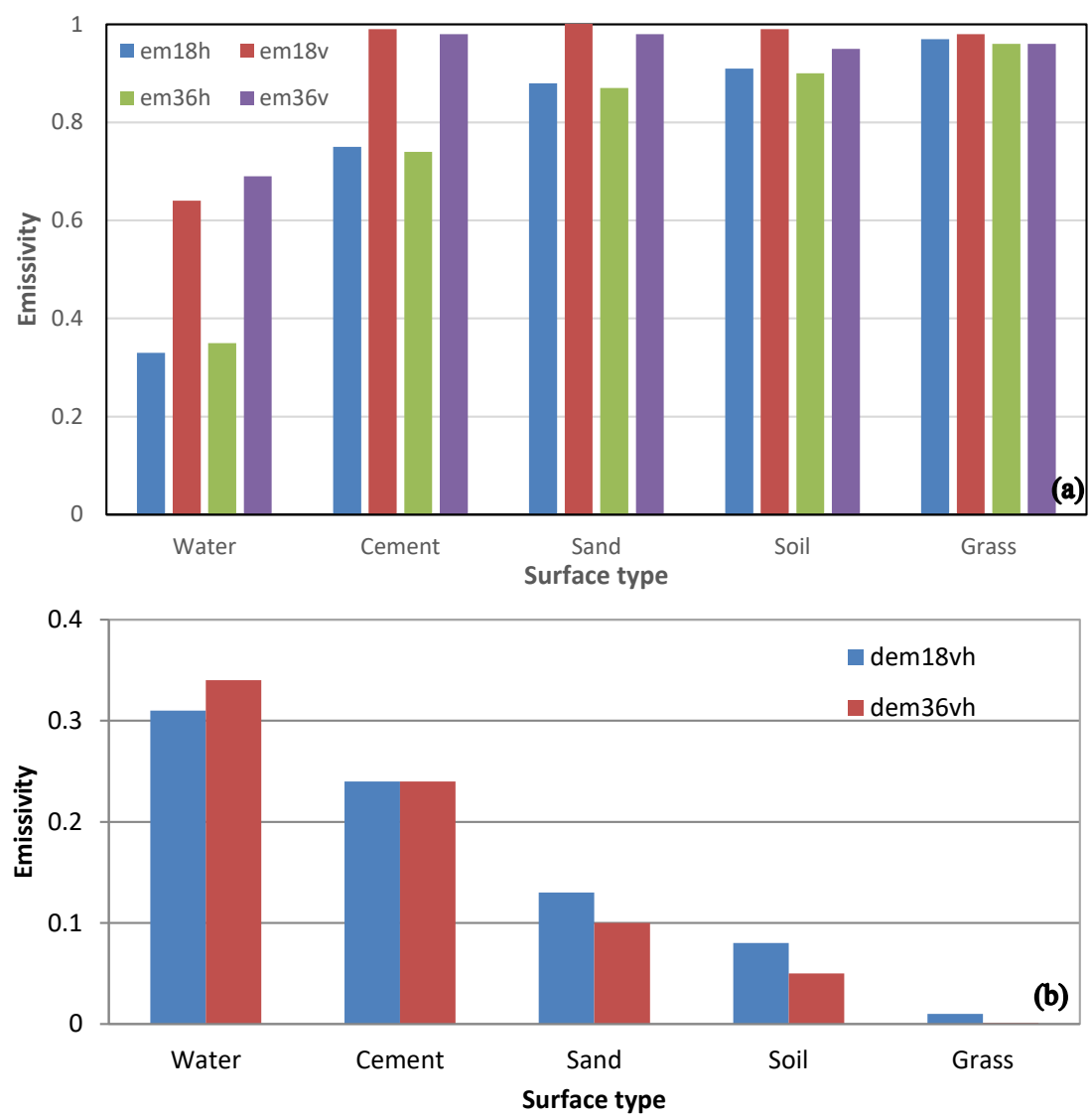

Fig. 7 Variations in the surface emissivity over different land surfaces at the

elevation angle of $36^{\circ}$

In addition to investigating the variations at a fixed angle, the variations in $\varepsilon$ at

The corresponding $\varepsilon_{\mathrm{v}}$ values over the four land surfaces are closer and exhibit a slightly decreasing trend within the range of $0.9-1.0$ with increasing elevation angle. 

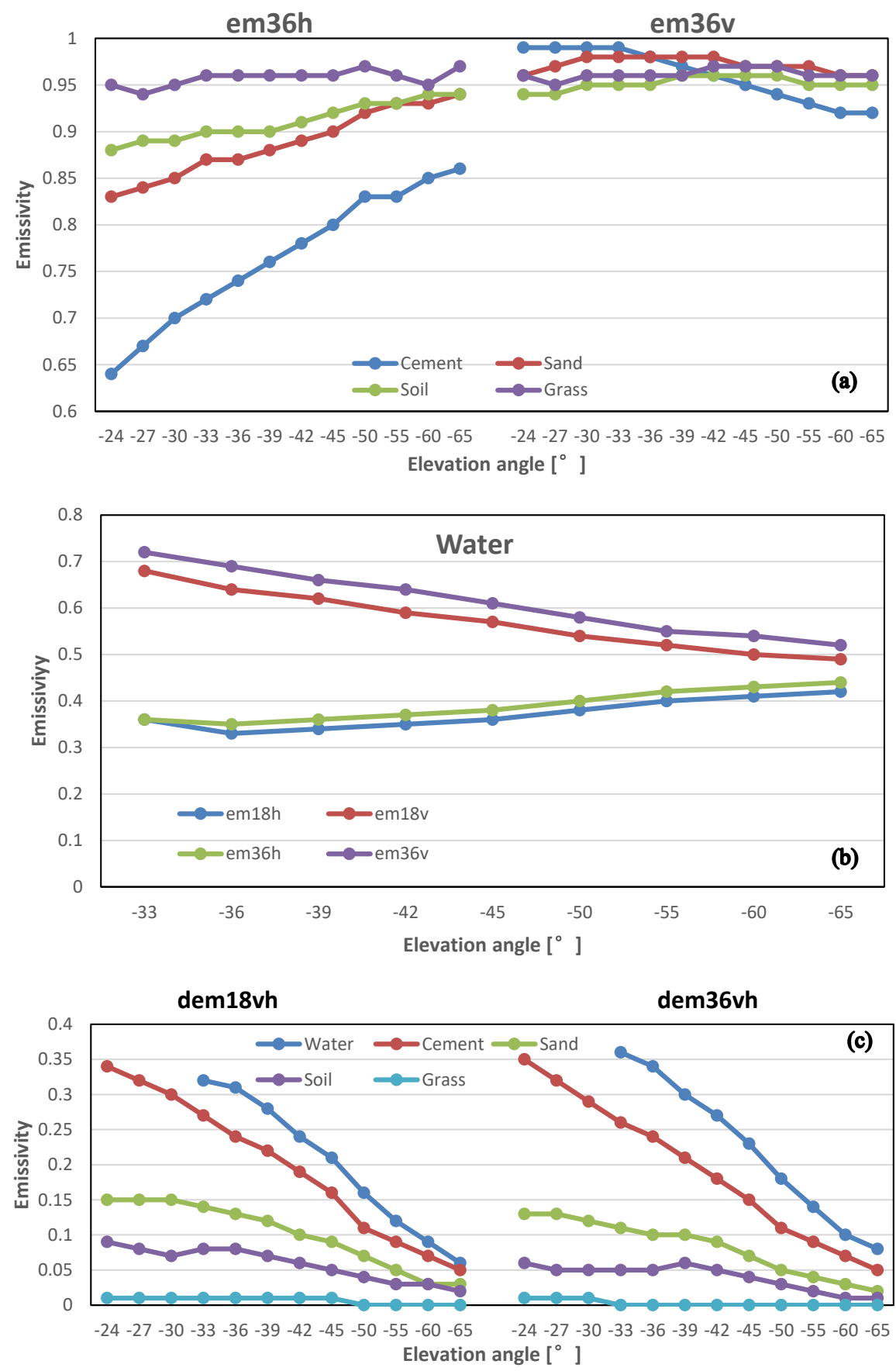

Fig. 8 Variations in the surface emissivity over different land surfaces(a,b) and

their $\varepsilon$ polarization differences $(c)$ with increasing elevation angle. 
393 As shown in Fig. 8b, the $\varepsilon$ values over water show considerably different variation

394 trends with the elevation angle from those over land surfaces: when the elevation angle changes from $-33^{\circ}$ to $-65^{\circ}, \varepsilon_{\mathrm{v}}$ reduces from 0.7 to 0.5 , while $\varepsilon_{\mathrm{h}}$ slightly increases within the vicinity of 0.4 . The $\varepsilon$ polarization differences $\left(\varepsilon_{\mathrm{v}}-\varepsilon_{\mathrm{h}}\right)$ in Fig. 8c present similar variation trends to those shown in Fig. $7 \mathrm{~b}$; that is, the $\varepsilon$ polarization difference decreases with increasing elevation angle, and the larger the polarization difference of $\varepsilon$ is (Fig. 7b), the greater the variation with the elevation angle (Fig. 8c). Hence, the decreasing trend of $\varepsilon$ is most obvious over water and cement, and $\varepsilon$ slightly changes over grass with increasing elevation angle. The variation in the $\varepsilon$ polarization difference at $36.5 \mathrm{GHz}$ with the elevation angle is similar to that at $18.75 \mathrm{GHz}$ over all

4035 test plots (results not shown).

404

405

406

407

408

409

\section{Summary}

In this paper, we introduce a ground mobile observation system for directly obtaining surface microwave emissivity estimates over five types of surfaces: water, cement, sand, soil and grass. The mobile observation system consists mainly of a dual-polarized ground-based microwave radiometer, a mobile platform, and auxiliary sensors, and the observation field comprises 5 test plots.

Based on the observed data from the mobile system, we preliminarily investigated the variation characteristics of the surface microwave emissivity over the five different land surfaces. The results show that the horizontally polarized emissivity is more sensitive to land surfaces than is the vertically polarized emissivity: 
415 the former decreases to 0.75 over cement and increases to 0.90 over sand and bare soil

416 and up to 0.97 over grass. Hence, the corresponding polarization difference is obvious over water $(>0.3)$ and cement (approximately 0.25 ) but reduces to 0.1 over sand and 0.05 over bare soil and almost 0.01 or close to zero over grass; this trend is similar to that of the $\mathrm{Tb}$ polarization difference. For different elevation angles, the horizontally/vertically polarized emissivities over the land surfaces obviously increase/slightly decrease with increasing elevation angle but exhibit the opposite trend over water. Moreover, the emissivity polarization difference decreases with increasing elevation angle, and the larger the emissivity polarization difference is over a certain surface, the greater the variation with the elevation angle. emissivity over multiple surfaces, and the system has worked stably since August 2018. The preliminary results from our observation system partly reflect similar variation trends to those reported by previous surface emissivity experiments, and some are more related to the variation in emissivity at different elevation angles. In parameterization scheme for given surfaces based on long-term observations.

\section{Acknowledgments}

This work was supported by National Natural Science Foundation of China [No. 
Calvet, J. C., Wigneron J. P., Chanzy. A.,Raju S., and Laguerre L.: Microwave dielectric proporeties of a silt-loam at high frequencies, IEEE Trans. Geosci. Remote sensing, 33, 634-642,doi: 10.1109/36.387579, 1995.

Fung A. K.: Microwave Scattering and Emission Models and Their Applications. Norwood, MA: Artech House, 1994.

Karbou, F., Aires F., Prigent C., and Eymard L.: Potential of Advanced Microwave Sounding Unit-A (AMSU-A) and AMSU-B measurements for atmospheric temperature and humidity profiling over land, Journal of Geophysical Research, 110, D07109, doi:10.1029/2004JD005318, 2005.

Hewison T. J.: Airborne measurements of forest and agricultural land surface emissivity at millimeter wavelengths. IEEE Trans. Geosci. Remote sensing., 39, 393-400, DOI:10.1109/36.905247, 2001.

Hewison, T. J., and English S. J.: Airborne retrievals of snow and ice surface emissivity at millimeter wavelengths. IEEE Trans. Geosci. Remote Sens., 37, 1871-1887, doi:10.1109/36.774700,1999.

Isaacs R. G., Jin Y. Q., Worsham R. D., Deblonde, G., Falcone, V. J.: The RADTRAN microwave surface emission models. IEEE Trans.Geosci. Remote sensing, 27, 433-440, DOI:10.1109/36.29563,1989.

Jones, A.S., Vonder Haar, T.H.: Retrieval of microwave surface emittance over land using coincident microwave and infrared satellite measurements, J. Geophys. Res.,102,13,609-13,626, https://doi.org/10.1029/97JD00797,1997.

Lemmetyinen, J., Derksen C., Toose, P., Proksch,C., Pulliainen, J., Kontu, A., Rautiainen, K., Seppänen, J., Hallikainen, M.: Simulating seasonally and spatially varying snow cover brightness temperature using HUT snow emission model and retrieval of a microwave effective grain size, Remote Sens. Environ.,156,71-95, http://dx.doi.org/10.1016/j.rse.2014.09.016,2015

Mazler C.: Seasonal evolution of microwave radiation from an oat field, Remote Sens. Environ., 31, 161-173, doi:10.1016/0034-4257(90)90086-2,1990.

Mazler C.: Passive microwave signatures of landscapes in winter, Meteorol. Atmos. Phys., 54, 241-260, https://doi.org/10.1007/BF01030063, 1994.

McNally A. P., Derber J. C., Wu W. S., Katz, B.B.: The use of TOVS level-1B radiances in the NCEP SSI analysis system, Quarterly Journal of the Royal Meteorological Society, 126, 689-724, https://doi.org/10.1002/qj.49712656315, 2000.

Mo, T., Schmugge, T.J.: A parameterization of the effect of surface roughness on microwave emission, IEEE Trans. Geosci. Remote Sens., 4, 481-486, doi: 10.1109/TGRS.1987.289860, 1987.

Moncet, J.L., P. Liang, J. F., Galantowicz, et al., 2011: Land surface microwave emissivities derived from AMSR-E and MODIS measurements with advanced quality control. J. Geophys. Res., 116, D16104, doi:10.1029/2010JD015429.

Montpetit, B., Royer, A., Roy, A., Langlois, A.: In-situ passive microwave emission model parameterization of sub-arctic frozen organic soils, Remote Sens. Environ.,205,112-118, http://dx.doi.org/10.1016/j.rse.2014.09.016, https://doi.org/10.1016/j.rse.2017.10.033,2018.

Morland, J. C., Grimes D.I.F., Dugdale, G., Hewison, T.J.: The Estimation of Land Surface Emissivities at $24 \mathrm{GHz}$ to $157 \mathrm{GHz}$ Using Remotely Sensed Aircraft Data, Remote Sens. Environ., 73, 323-336, https://doi.org/10.1016/S0034-4257(00)00108-5,2000. 
Morland, J. C., Metcalfe J., and Walker A.: Microwave remote sensing of soil moisture in southern Ontario: Aircraft and satellite measurements at 19 and $37 \mathrm{GHz}$, Radio Sci., 38, 8073, doi:10.1029/2002RS002677, 2003.

Njoku, E.G., and O'Neill P. E.: Multifrequency microwave radiometer measurements of soil moisture, IEEE Trans. Geosc. Remote Sens., 20, 468-475, doi:10.1109/TGRS.1982.350412, 1982.

Ruston R. C., Vonder Haar T. H.: Characterization of summertime microwave emissivity from the Special Sensor Microwave Imager over the conterminous United States, J. Geophys. Res., 109, D19103, doi:10.1029/2004JD004890, 2004.

Prigent, C., W. B. Rossow, E. Matthews, Microwave land surface emissivities estimated from SSM/I observations, J. Geophys. Res.,102, 21867-21890, https://doi.org/10.1029/97JD01360,1997.

Prigent, C., Rossow, W. B., Matthews, E., and Marticorena, B.: Microwave radiometric signatures of different surface types in deserts, Journal of Geophysical Research, 104, 12147-12158, doi: 10.1029/1999JD900153, doi:10.1029/1999JD900153, 1999.

Prigent, C., Wigneron, J. P., Rossow, W. B., and Pardo-Carrionet, J.R.: Frequency and angular variations of land surface microwave emissivities: Can we estimate SSM/T and AMSU emissivities from SSM/I emissivities? IEEE Trans.Geosci. Remote sensing, 38, 2373-2386, doi:10.1109/36.868893, 2000.

Prigent, C., Aires F., and Rossow W. B.: Land surface microwave emissivities over the globe for a decade, Bull. Amer. Meteorol. Soc., 87, 1573 - 1584, https://doi.org/10.1175/BAMS-87-11-1573, 2006.

Schwartz, C. S., Liu, Z. Q., Chen, Y., Huang, X.Y.: Impact of assimilating microwave radiances with a limited-area ensemble data assimilation system on forecasts of Typhoon Morakot, Weather Forecasting, 27, 424-437, https://doi.org/10.1175/WAF-D-11-00033.1,2012.

Ulaby, F. T., Moore, R. K., Fung, A. K.: Microwave Remote Sensing: Active and Passive. Vol. 3: From Theory Applications. Addison-Wesley Publ. Company, Readings, Massachusettes, 1986.

Wang, J. R. and Choudhury, B. J.: Remote sensing of soil moisture content over bare field at 1.4 GHz frequency, J. Geophys. Res., 86, 5277-5282, 1981.

Wigneron, J. P., Guyon, D., Calvet, J. C., Courrieer G., Bruguier N.: Monitoring coniferous forest characteristics using a multifrequency microwave radiometry, Remote Sens. Environ., 60, 299-310, doi:10.1016/S0034-4257(96)00212-X,1997.

Weng, F., Yan, B., Grody N.C.: A microwave land emissivity model, J. Geophys. Res., 106, 20,115-20,123, https://doi.org/10.1029/2001JD900019, 2001.

Xie, Y., Shi, J., Ji, D., Zhong, J., Fan, S.: A Parameterized Microwave Emissivity Model for Bare Soil Surfaces, Remote sensing, 9, 155-170, https://doi.org/10.3390/rs9020155, 2017. 